\title{
Correction to: Does antrum size matter in sleeve gastrectomy? A prospective randomized study
}

\author{
Francesco Pizza 10 - Dario D'Antonio ${ }^{1}$ - Francesco Saverio Lucido ${ }^{2}$. Claudio Gambardella ${ }^{2}$. \\ Juan Antonio Carbonell Asíns ${ }^{3} \cdot$ Chiara Dell'Isola $^{4} \cdot$ Salvatore Tolone ${ }^{2}$
}

Published online: 4 August 2020

(c) Springer Science+Business Media, LLC, part of Springer Nature 2020

\section{Correction to: Surgical Endoscopy} https://doi.org/10.1007/s00464-020-07811-1

This article was updated to correct Juan Antonio Carbonell Asíns' name in the author listing: Juan Antonio (given name) Carbonell Asíns (family name).

Publisher's Note Springer Nature remains neutral with regard to jurisdictional claims in published maps and institutional affiliations.

The original article can be found online at https://doi.org/10.1007/ s00464-020-07811-1.

Francesco Pizza

Francesco_pizza@libero.it

1 Department of Surgery, Hospital "A. Rizzoli", Aslnapoli2nord, Naples, Italy

2 Division of General, Mininvasive and Bariatric Surgery, University of Campania “Luigi Vanvitelli”, Naples, Italy

3 Bioinformatics and Biostatistics Unit, Biomedical Research Institute (INCLIVA), Valencia, Spain

4 Department of Infectious Diseases, AORN "Dei Colli”, Naples, Italy 